\title{
Green odor attenuates a cold pressor test-induced cardiovascular response in healthy adults
}

\author{
Takakazu Oka*1, Sota Hayashida1, Yuko Kaneda1, Masaki Takenaga1, \\ Yoko Tamagawa ${ }^{1}$, Sadatoshi Tsuji ${ }^{1}$ and Akikazu Hatanaka ${ }^{2}$
}

Address: ${ }^{1}$ Psychosomatic Medicine Division, Department of Neurology, University of Occupational and Environmental Health, Japan. Iseigaoka 1-1, Yahatanishi-ku, Kitakyushu, 807-8555, Japan and 2Department of Biochemistry, Yamaguchi University, Yamaguchi, 753-8511, Japan

Email: Takakazu Oka* - toka@med.uoeh-u.ac.jp; Sota Hayashida - hsota@med.uoeh-u.ac.jp; Yuko Kaneda - y-kaneda@med.uoeh-u.ac.jp; Masaki Takenaga - takenaga@med.uoeh-u.ac.jp; Yoko Tamagawa - y-ii@med.uoeh-u.ac.jp; Sadatoshi Tsuji - tsujisa@med.uoeh-u.ac.jp; Akikazu Hatanaka - midorinf@utopia.ocn.ne.jp

* Corresponding author

Published: 15 January 2008

BioPsychoSocial Medicine 2008, 2:2 doi:10.1186/1751-0759-2-2

This article is available from: http://www.bpsmedicine.com/content/2/I/2

(c) 2008 Oka et al; licensee BioMed Central Ltd.

This is an Open Access article distributed under the terms of the Creative Commons Attribution License (http://creativecommons.org/licenses/by/2.0), which permits unrestricted use, distribution, and reproduction in any medium, provided the original work is properly cited.

\begin{abstract}
Background: Green odor, a mixture of equal amounts of 2E-hexenal (leaf aldehyde) and 3Zhexenol (leaf alcohol) has been demonstrated to have an anti-stress effect in rats. This study investigated whether or not green odor also has an anti-stress effect in humans.
\end{abstract}

Methods: Changes in blood pressure, heart rate, and the skin temperature of a fingertip were observed after presenting green odor at a concentration of $0.03 \%$ or vehicle via inhalation through the nose for $10 \mathrm{~min}$ to eight healthy normotensive adults. We also assessed the pleasantness of green odor and its effect on mood states via assessment with the Profile of Mood States (POMS) questionnaire. Cardiovascular response to green odor and the vehicle were compared among II additional healthy adults by use of the cold pressor test.

Results: Of 19 subjects, 15 (79\%) reported that the green odor was pleasant. Green odor had no effect on blood pressure, heart rate, skin temperature, or POMS score under non-stressful conditions. In the second experiment, green odor attenuated cold pressor test-induced increases in systolic and diastolic blood pressure and facilitated the recovery of skin temperature.

Conclusion: These findings suggest that green odor has an anti-stress effect in healthy humans.

\section{Background}

The odor of green leaves arises from eight volatile compounds that include 3Z-hexenol (leaf alcohol) and $2 E$ hexenal (leaf aldehyde) [1]. These compounds are synthesized in the chloroplast membrane in green leaves and have a wide variety of biological effects including acting as plant-to-plant messengers in allopathy, insect-attracting pheromone-like substances, and bactericidal-like substances [2] (for review, see [3]). It has been reported that the odor of a mixture containing equal amounts of 3Zhexenol and 2E-hexenal, "green odor," has an anti-fatigue effect in rats [4] and humans [5]. 3Z-hexenol, a component of green odor, is reported to have an anxiolytic effect in mice [6] and to decrease the amplitude of P300 activity in humans [7]. Recent studies have demonstrated that green odor has an anti-stress effect in rats. For example, green odor blocked immobilization stress-induced adren- 
ocorticotropic hormone (ACTH) release [8] and cage change stress-induced hyperthermia [9].

We hypothesized that green odor also has an anti-stress effect in humans. In the present study, we assessed the effect of green odor on blood pressure (BP), heart rate (HR), and skin temperature (Ts), as well as subject perception of odor pleasantness and a possible change in mood under non-stressful conditions. We then assessed the effect of green odor on cardiovascular response during the stress of a cold pressor test. In this report, we demonstrate for the first time that green odor does exhibit an anti-stress effect in humans.

\section{Methods \\ Subjects}

Nineteen healthy normotensive adults without any disorder of the olfactory system participated after giving informed consent. In experiment 1 , eight subjects participated (four men, four women) age 23-46 years (31.8 \pm 3.1 years, mean \pm standard error of the mean (SEM)). In experiment 2, a different eleven subjects participated (six men, five women) age $21-48$ years (34.5 \pm 3.7 years). All subjects were requested to avoid using fragrant cosmetics or having strong smelling meals on the day of the experiment.

\section{Methods}

Experiments were carried out in a quiet, air-conditioned room kept at $23-24^{\circ} \mathrm{C}$ between 1 p.m. and 5 p.m. Experiments were conducted twice under both conditions with green odor and with a vehicle, with the same subjects, at the same time on different days at least seven days apart. Subjects were randomly divided into two groups to ensure counterbalance.

Experiments were approved by the Ethics Committee of the University of Occupational and Environmental Health, Japan and conducted in accordance with their guidelines.
Experiment I: Effects of green odor on perception of pleasantness, mood state, and cardiovascular parameters under non-stressful conditions

After entering the experiment room, the subject was asked to sit on a chair and relax for $20 \mathrm{~min}$. Meanwhile, a Japanese version of the Profile of Mood States (POMS) survey [10] was filled in. POMS is a self-rating questionnaire used for measuring six mood states: tension-anxiety (T-A), depression (D), anger-hostility (A-H), vigor (V), fatigue (F), and confusion (C). Automatic monitoring of BP and HR from the left arm was then done each minute for at least seven minutes total. Skin temperature (Ts) of the ventral surface of the right index fingertip was also monitored continuously. When BP, HR, and Ts became stable, values were recorded for three min. An average of three recordings served as the baseline value. After baseline measurement, a sheet of filter paper $(30 \times 150 \mathrm{~mm})$ was impregnated with an aliquot of test solution containing $100 \mathrm{mg}$ green odor or vehicle and was held $2 \mathrm{~cm}$ from the tip of the nose for presentation. Ten min after exposure of test solution, the paper was removed. BP, HR, and Ts were monitored for an additional five min. After the experiment, subjects again completed the POMS and rated the intensity and pleasantness of the odor. Odor intensity ( $0-$ $5)$ and degree of pleasantness $(-4-+4)$ were assessed based on a six-point rating scale of odor intensity and a nine-point rating scale of pleasantness/unpleasantness, respectively. These scales are commonly used by the Ministry of the Environment and described elsewhere (Table 1) [7]. BP and HR were measured by a sphygmomanometer (ListMini, Nippon Colin Co. Ltd., Tokyo Japan). Ts was recorded continuously by a copper-constantan thermocouple that was connected to a digital thermometer (ThermoController, Unique Medical, Fukuoka, Japan).

\section{Preparation of green odor}

Green odor, a mixture of equal amounts of 2E-hexenal and 3Z-hexenol, was diluted with the odorless solvent triethyl citrate (TEC) to a concentration of $0.03 \%(\mathrm{w} / \mathrm{w})$. TEC served as the vehicle. 2E-hexenal, 3Z-hexenol, and TEC were generous gifts from Soda Aromatic Co. Ltd., Tokyo.

Table I: Six-point rating scale of odor intensity and nine-point rating scale of pleasantness/unpleasantness.

(I) Six-point rating scale of odor intensity

\section{0: Odorless}

I: Barely perceptible odor

2: Faint but source-discriminative odor

3: Easily perceptible odor

4: Strong odor

5: Extremely strong odor
(2) Nine-point rating scale of pleasantness/unpleasantness.

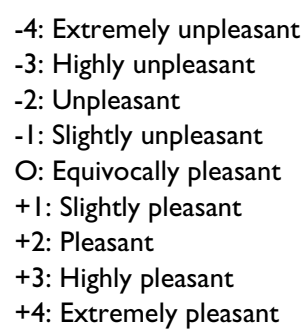

-4: Extremely unpleasant

-3: Highly unpleasant

-2: Unpleasant

-I: Slightly unpleasant

O: Equivocally pleasant

+ I: Slightly pleasant

+2 : Pleasant

+3: Highly pleasant

+4: Extremely pleasant 
Experiment 2: Effect of green odor on cold pressor test-induced changes in $B P, H R$, and $T s$

This experiment was performed in the same room as was used for experiment 1. After entering the experiment room, the subject sat on a chair and relaxed for at least 20 min. BP, HR, and Ts were then monitored automatically each $\min$ for at least seven $\mathrm{min}$. When these values became stable, they were recorded for a further three min. An average of three values was used as the baseline value. Subsequently, subjects were presented with green odor or vehicle as was done in experiment 1 . The subjects then immersed their right hand, past the level of the wrist, for one min in a bucket filled with slushy ice water $\left(4^{\circ} \mathrm{C}\right)$ (cold pressor test, CPT). Ten min after starting the CPT, the paper was removed and BP, HR, and Ts were observed for an additional $20 \mathrm{~min}$. After recording was finished, the subject rated the intensity and unpleasantness of pain experienced during CPT on a 0-10 numerical rating scale, in which 0 indicates "no pain" or "not unpleasant" and 10 represents "the worst possible pain imaginable" or "the worst unpleasantness." Subjects also rated the intensity and pleasantness of the odor.

\section{Statistical analysis}

Values were expressed as means \pm SEM. The intensity and pleasantness of the odor were examined by the MannWhitney U test. POMS scores and CPT-induced pain intensity and discomfort were examined by the paired $t$ test and Wilcoxon signed-rank test. Differences in BP and HR from baseline to one min following CPT (the maximum response time) were calculated and between group differences in these "deltas" were analyzed by the paired $t$ test. Differences in Ts from baseline were calculated for every one min interval up to $10 \mathrm{~min}$ following completion of CPT, and the area under the curve between 0 min to 10 min following CPT $\left(\mathrm{AUC}_{0-10 \mathrm{~min}}\right)$ was calculated and between group comparisons were done using the paired $t$ test.

\section{Results \\ Effect of green odor on pleasantness and mood state}

The intensity and pleasantness of the green odor and vehicle are shown in Table 2, which summarizes data obtained from experiments 1 and 2. Subjects reported green odor to be more intense $(\mathrm{p}<0.01)$ and more pleasant $(\mathrm{p}<0.05)$ than the vehicle, TEC. Of 19 subjects, 15 (79\%) reported that green odor was slightly pleasant, pleasant, or highly pleasant. One subject reported that green odor was slightly unpleasant. However, this subject also reported that the vehicle was slightly unpleasant, so the response to green odor may not have been due to the green odor itself, but rather to TEC (Table 2). The effects of green odor on POMS scores are shown in Table 3 . Neither green odor nor TEC changed POMS subscale scores.

\section{Effect of green odor on BP, HR, and Ts under non-stressful conditions}

Changes in systolic blood pressure (SBP), diastolic blood pressure (DBP), HR, and Ts were compared between exposure to the green odor and to the vehicle. In Table 4, baseline values and values at $1 \mathrm{~min}$ and $10 \mathrm{~min}$ after presentation of odor are shown for comparison with the results of experiment 2. No parameter was significantly different between green odor and vehicle at any observation point. Furthermore, SBP, DBP, HR, and Ts at $10 \mathrm{~min}$ did not differ from baseline values for either exposure (Table 4).

\section{Effects of green odor on CPT-induced cardiovascular responses}

Baseline values for SBP, DBP, and HR during exposure to green odor were $112.8 \pm 3.5 \mathrm{mmHg}, 62.1 \pm 3.2 \mathrm{mmHg}$, $68.6 \pm 3.2 \mathrm{bpm}$, and $33.5 \pm 0.6^{\circ} \mathrm{C}$, respectively. Values for subjects exposed to vehicle were $113.6 \pm 4.3 \mathrm{mmHg}, 61.6$ $\pm 3.8 \mathrm{mmHg}, 71.1 \pm 3.7 \mathrm{bpm}$, and $34.1 \pm 0.4^{\circ} \mathrm{C}$, respectively (no difference in baseline values). Both SBP and DBP increased just after initiation of the CPT in 9 of 11 subjects. BP readings were highest one min after starting the CPT and returned to baseline levels within three min.

Table 2: Intensity and pleasantness/unpleasantness of green odor and vehicle.

\begin{tabular}{|c|c|c|c|c|c|c|}
\hline $\begin{array}{l}\text { Rating of odor } \\
\text { intensity } * *\end{array}$ & 0 & 1 & 2 & 3 & 4 & 5 \\
\hline Green odor (n) & 0 & 0 & 5 & 10 & 4 & 0 \\
\hline Vehicle $(n)$ & 2 & 4 & 9 & 4 & 0 & 0 \\
\hline $\begin{array}{l}\text { Rating of } \\
\text { pleasantness/ } \\
\text { unpleasantness * }\end{array}$ & -1 & 0 & I & 2 & 3 & 4 \\
\hline Green odor (n) & 1 & 3 & 5 & 8 & 2 & 0 \\
\hline Vehicle $(n)$ & I & 9 & 5 & 4 & 0 & 0 \\
\hline
\end{tabular}

$N=19 . * *: p<0.01 ; *: p<0.05$ 
Table 3: The effect of green odor on mood states under non-stressful conditions.

\begin{tabular}{llll}
\hline POMS subscale & Pre-exposure & Post-exposure & P value \\
\hline T-A & $9.9 \pm 2.3$ & $8.9 \pm 1.9$ & n.s. \\
D & $10.4 \pm 4.1$ & $10.1 \pm 4.4$ & n.s. \\
A-H & $8.0 \pm 2.1$ & $6.9 \pm 1.9$ & n.s. \\
V & $10.9 \pm 1.9$ & $12.0 \pm 2.5$ & n.s. \\
F & $7.3 \pm 1.5$ & $7.8 \pm 1.7$ & n.s. \\
C & $6.9 \pm 1.2$ & $8.3 \pm 1.8$ & n.s.
\end{tabular}

$N=8$. Mean \pm SEM. n.s.: not significant. POMS: Profile of Mood States; T-A: tension-anxiety; D: depression; A-H: anger-hostility; V: vigor; F: fatigue; C: confusion.

Figure 1 compares changes in SBP, DBP, and HR at one min after initiation of CPT from baseline levels $(\triangle \mathrm{SBP}$, $\triangle \mathrm{DBP}, \Delta \mathrm{HR})$ for green odor and vehicle exposures. At one min after the start of the CPT, $\triangle \mathrm{SBP}$ for green odor was 5.3 $\pm 2.8 \mathrm{mmHg}$, whereas it was $16.2 \pm 4.1 \mathrm{mmHg}$ for the vehicle. The $\triangle \mathrm{DBP}$ for green odor was $-3.3 \pm 1.2 \mathrm{mmHg}$, whereas it was $7.7 \pm 3.0 \mathrm{mmHg}$ for the vehicle. Both $\triangle \mathrm{SBP}$ and $\triangle \mathrm{DBP}$ were significantly smaller for the green odor group than for the vehicle group ( $\mathrm{p}<0.05)$ (Fig. 1). In contrast, BP decreased for two subjects after initiation of CPT. Their CPT-induced decrease was most evident one min after the start of the test; this change was also attenuated with green odor exposure. CPT-induced changes in the SBP of all subjects are shown in Figure 2.

Ts decreased one min after initiation of the CPT and returned gradually to baseline level within $30 \mathrm{~min}$ for all subjects under both exposures (green odor and vehicle). Changes in Ts from the baseline value $(\Delta \mathrm{Ts})$ were com- pared for green odor and vehicle. The $\Delta \mathrm{Ts}$ one min after initiation of CPT were $-18.0 \pm 0.8^{\circ} \mathrm{C}$ for green odor and $18.9 \pm 0.6^{\circ} \mathrm{C}$ for vehicle. The $\Delta$ Ts one min after initiation of CPT did not differ between exposures. Figure 3 shows the calculation and comparison of $\mathrm{AUC}_{0-10 \mathrm{~min}}$ values for the two exposures. The $\mathrm{AUC}_{0-10 \text { min }}$ value for green odor ($\left.72.9 \pm 8.6^{\circ} \mathrm{C} \cdot \mathrm{min}\right)$ was significantly different from that for vehicle $\left(-92.0 \pm 9.3^{\circ} \mathrm{C} \cdot \mathrm{min}\right)(\mathrm{p}<0.05)$, suggesting that green odor facilitates recovery of Ts to the baseline level during the CPT condition.

Effect of green odor on pain intensity and unpleasantness Most subjects perceived the CPT to be painful. When exposed to green odor, subjects rated CPT-induced pain intensity to be $7.3 \pm 1.0$ compared with $7.0 \pm 1.1$ when exposed to vehicle. They rated unpleasantness of pain as $6.8 \pm 1.0$ when exposed to green odor compared with 6.2 \pm 1.2 when exposed to vehicle. Neither pain intensity nor

Table 4: The effect of green odor on physiological parameters under non-stressful conditions. Subjects were exposed to green odor or vehicle for 10 minutes.

\begin{tabular}{|c|c|c|c|}
\hline & Green odor & Vehicle & $\mathrm{p}$-value \\
\hline \multicolumn{4}{|c|}{ Systolic blood pressure $(\mathrm{mmHg})$} \\
\hline At baseline & $105.6 \pm 3.2$ & $106.4 \pm 5.0$ & n.s. \\
\hline$I \min$ & $104.9 \pm 4.8$ & $106.0 \pm 4.1$ & n.s. \\
\hline $10 \mathrm{~min}$ & $108.4 \pm 5.1$ & $108.3 \pm 4.5$ & n.s. \\
\hline \multicolumn{4}{|c|}{ Diastolic blood pressure $(\mathrm{mmHg})$} \\
\hline At baseline & $59.3 \pm 3.3$ & $61.3 \pm 4.3$ & n.s. \\
\hline $\mathrm{Imin}$ & $58.9 \pm 3.5$ & $59.6 \pm 4.2$ & n.s. \\
\hline $10 \mathrm{~min}$ & $54.0 \pm 5.1$ & $60.4 \pm 4.1$ & n.s. \\
\hline \multicolumn{4}{|c|}{ Heart rate (beats/min) } \\
\hline At baseline & $69.4 \pm 2.7$ & $66.4 \pm 1.6$ & n.s. \\
\hline $1 \mathrm{~min}$ & $71.0 \pm 4.0$ & $63.7 \pm 2.2$ & n.s. \\
\hline $10 \mathrm{~min}$ & $70.5 \pm 2.8$ & $64.8 \pm 1.3$ & n.s. \\
\hline \multicolumn{4}{|c|}{ Skin temperature $\left({ }^{\circ} \mathrm{C}\right)$} \\
\hline At baseline & $32.2 \pm 2.8$ & $32.9 \pm 3.5$ & n.s. \\
\hline $\mathrm{min}$ & $33.0 \pm 2.3$ & $32.8 \pm 3.6$ & n.s. \\
\hline $10 \mathrm{~min}$ & $31.1 \pm 4.3$ & $33.2 \pm 3.4$ & n.s. \\
\hline
\end{tabular}

$N=8$. Mean \pm SEM. N.s.:not significant. 


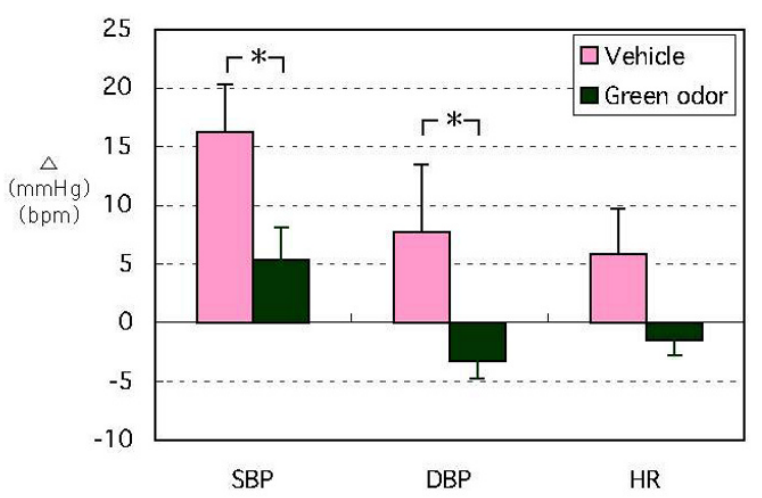

Figure I

The effect of green odor or vehicle on CPT-induced changes in SBP, DBP, and HR. Changes in SBP, DBP, and HR one min after the start of CPT versus baseline levels ( $\triangle \mathrm{SBP}, \triangle \mathrm{DBP}$, and $\triangle \mathrm{HR}$ ) were evaluated. $\mathrm{N}=9$. Means $\pm \mathrm{SEM}$. *: $\mathrm{p}<0.05$. Abbreviations: CPT, cold pressor testing; SBP, systolic blood pressure; DBP, diastolic blood pressure; HR, heart rate.

the unpleasantness of pain differed for exposure to green odor versus vehicle (Fig. 4).

\section{Discussion}

The present study demonstrated that green odor attenuated the increase in SBP and DBP induced by CPT and facilitated recovery of Ts without having any effect on these parameters, under non-stressful conditions. These findings are the first to suggest that green odor exhibits an anti-stress effect in healthy, normotensive human adults.

The inhibitory effect of green odor on cardiovascular response to the CPT may not be a secondary effect due to its hypoalgesic action [4] because the scores for CPTinduced pain intensity and unpleasantness did not differ for green odor versus vehicle. A previous study reported that green odor increased the mechanical pain threshold in humans [4]. It is unknown why the effect of green odor on CPT-induced pain obtained in the current study is different from the findings obtained in the previous study. One possible explanation is that the other research group assessed the effect of green odor on mechanical pain threshold, whereas our study investigated the effect on thermal pain. The effect of green odor on pain might differ depending on modality. The anti-stress effect associated with green odor does not appear to be induced secondarily through change in an emotional state such as reduced anxiety or anger, because neither the tension-anxiety nor

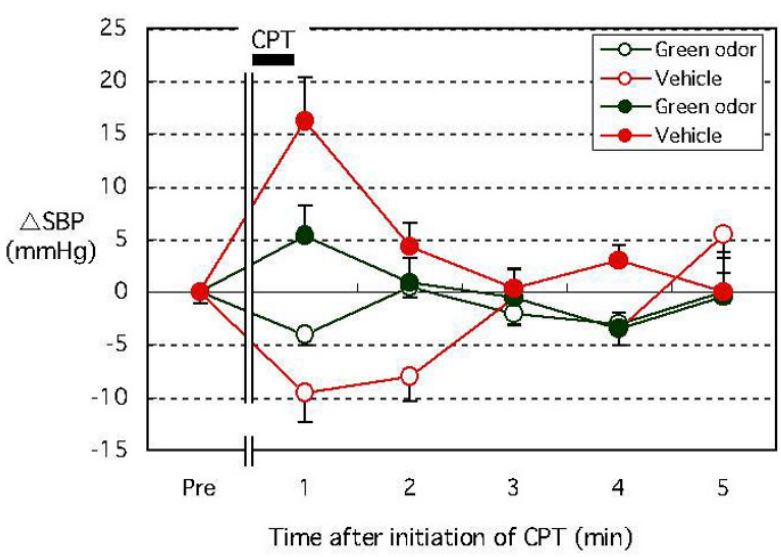

Figure 2

The effect of green odor or vehicle on CPT-induced changes in SBP. Changes in SBP $(\triangle \mathrm{SBP})$ in subjects whose SBP increased (filled circle, $n=9$ ) after initiation of CPT and in subjects whose SBP decreased (open circle, $n=2$ ) after initiation of CPT are shown. Means \pm SEM. Abbreviations: CPT, cold pressor testing; SBP, systolic blood pressure.

hostility-anger scores of the POMS changed with exposure to green odor.

Stress is characterized by activation of the hypothalamicpituitary-adrenocortical (HPA) axis and sympatheticadrenomedullary system (SAM). In rats, green odor has been found to attenuate immobilization stress-induced increases in plasma ACTH levels [8] and reduce psychological stress-induced hyperthermia [9]. As the sympathetic nervous system plays an important role in psychological stress-induced hyperthermia [11-13], findings from these animal studies suggest that green odor has an inhibitory effect on stress-induced activation of both the HPA axis and the SAM. In this study, green odor attenuated the CPT-induced increase in BP.

In hypertensive patients, the sympathetic nervous system is over-reactive, and stress-induced increases in BP are greater than in healthy subjects. Therefore, in some hypertensive patients, psychological stress makes blood pressure difficult to control. This characteristic of green odor, to attenuate a thermal stress-induced change in $\mathrm{BP}$, might be beneficial in treating hypertensive patients whose $\mathrm{BP}$ readings increase dramatically under conditions of psychological stress [14]. In contrast, interestingly, BP decreased following initiation of CPT in two subjects. It is uncertain why these subjects showed a different stress response pattern from the other subjects. However, green odor attenuated the CPT-induced decrease in BP in these 
(A)

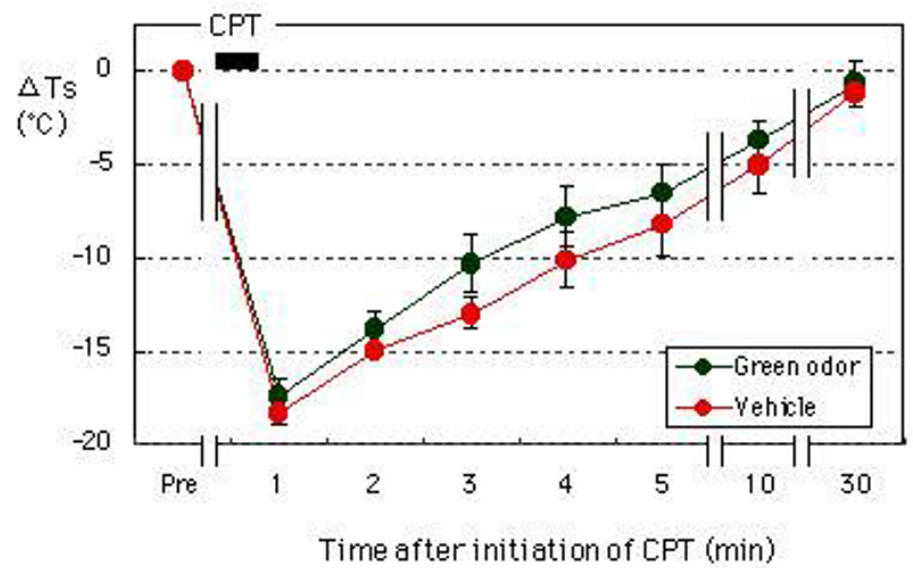

(B)

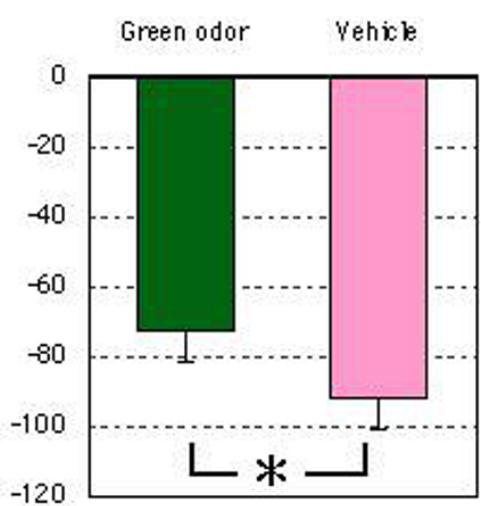

\section{Figure 3}

The effect of green odor or vehicle on recovery of baseline Ts following initiation of CPT. (A) Changes in Ts after the start of

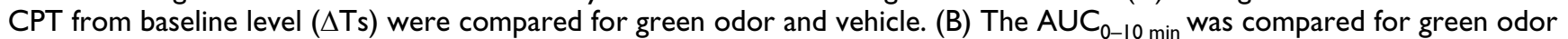
and vehicle. $\mathrm{N}=$ I I. Means \pm SEM. *: $\mathrm{p}<0.05$. Abbreviations: Ts, skin temperature; CPT, cold pressor testing.

subjects. Thus, it appears that green odor may inhibit stress-induced decreases in BP as well as increases in BP.

\section{Concentration of green odor}

In the present study, we investigated the effect of green odor at a concentration of $0.03 \%$ for the following reasons. Firstly, animal studies have demonstrated that green odor at this concentration has an anti-stress effect [8,9]. Secondly, our pilot study, conducted before the currently reported work, showed that the concentration range at which the majority of subjects reported green odor as pleasant was around $0.03 \%$. In that study, we examined the pleasantness of equal amounts of 3Z-hexenol and $2 E$ hexenal at different concentrations: $0.003 \%, 0.03 \%$, and $0.3 \%$. Twenty percent of the subjects reported 3Z-hexenol and $2 E$-hexenal at $0.3 \%$ to be extremely strong and unpleasant (data not shown). Even though $0.3 \%$ green odor may have a stronger anti-stress effect than at a lower concentration, the odor may not be clinically applicable as stress-reducing aromatherapy if subjects find it unpleasant. Therefore, we decided to conduct our major experiments using a concentration that would probably not be uncomfortable for most subjects: Indeed, the $0.03 \%$ concentration of $3 Z$-hexenol and $2 E$-hexenal was perceived as pleasant by $79 \%$ of subjects. However, as the next step in our research, it will be important to investigate the dosedependency of green odor's anti-stress effect to determine the concentration that exhibits maximal effect and to elucidate if green odor still has an anti-stress effect in adults who find green odor unpleasant.

\section{Possible neural mechanisms}

The precise mechanisms in the central nervous system through which green odor exerts its anti-stress effect are not fully understood. Forced swimming stress-induced expression of Fos-immunoreactivity in the paraventricular nucleus of the thalamus (PVT) of rats was attenuated by green odor [15]. The PVT is thought to play a pivotal role in modulating forebrain processing of stress-related information and is also implicated directly or indirectly in the generation of behavioral, endocrine, and autonomic

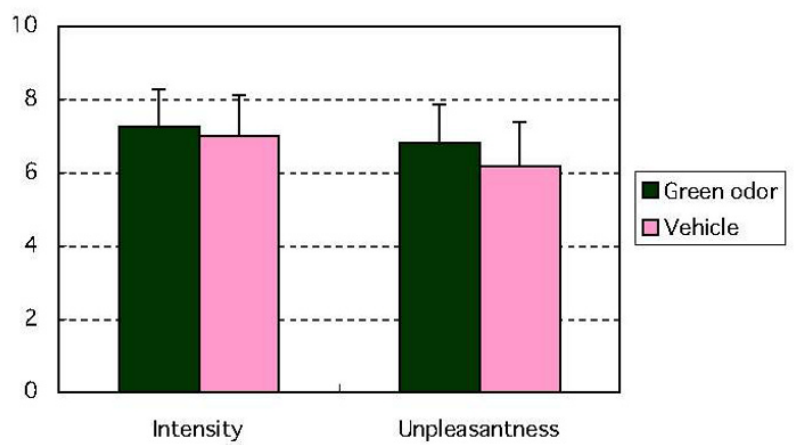

Figure 4

The effect of green odor or vehicle on intensity and unpleasantness of pain induced by cold pressor testing. 
responses to stress $[16,17]$. Therefore, it is possible that the anti-stress effect of green odor is achieved through inhibition of PVT neurons [15]. A positron emission tomography study using rhesus monkeys demonstrated that green odor activated the anterior cingulate gyrus as well as olfactory-related regions such as the prepyriform area, substantia innominata, and orbitofrontal cortex [18]. Given the crucial role of the anterior cingulate gyrus in processing emotion and affective behavior [19], activation of its neurons may also contribute to the anti-stress effect of green odor.

\section{Conclusion}

This study suggests that green odor has an anti-stress effect in healthy adults and may have potential for clinical aromatherapy.

\section{Abbreviations}

ACTH: Adrenocorticotropic hormone; BP: Blood pressure; HR: Heart rate; Ts: Skin temperature; POMS: Profile of Mood States; T-A: Tension-anxiety; D: Depression; A-H: Anger-hostility; V: Vigor; F: Fatigue; C: Confusion; TEC: Triethyl citrate; CPT: Cold pressor test; AUC: Area under the curve; SBP: Systolic blood pressure; DBP: Diastolic blood pressure; HPA: Hypothalamic-pituitary-adrenocortical; SAM: Sympathetic-adrenomedullary system; PVT: Paraventricular nucleus of the thalamus.

\section{Competing interests}

The author(s) declare that they have no competing interests.

\section{Authors' contributions}

TO designed the study protocol and drafted the manuscript. TO, SH, YK, MT, and YT conducted the experiments and analyzed the data. ST supervised the experiments. AH supervised the whole green odor project. All authors read and approved the final manuscript.

\section{Acknowledgements}

We greatly acknowledge Dr. Kota Sano, Soda Aromatic Co. Ltd., for providing $2 E$-hexenal, $3 Z$-hexenol, and TEC.

\section{References}

I. Hatanaka A: The fresh green odor emitted by plants. Food Rev Int 1996, 12:303-50.

2. Nakamura S, Hatanaka A: Green-leaf-derived C6-aroma compounds with potent antibacterial action that act on both Gram-negative and Gram-positive bacteria. J Agric Food Chem 2002, 50:7639-44.

3. Hatanaka A: So-called "green odor" as plant origin - chemistry and biochemistry. Seikagaku 2003, 75: $14 \mid 4-28$.

4. Aou S, Mizuno M, Matsunaga Y, Kubo K, Li XL, Hatanaka A: Green odor reduces pain sensation and fatigue-like responses without affecting sensorimotor function. Chem Senses 2005, 30(Suppl I):i262-3.

5. Watanabe Y, Sasabe T, Yamaguti K, Kobayashi M, Yamamoto S, Kuratsune H, Sano K, Hatanaka A, Tsukada H, Onoe H: Prevention and/or recovery effects by green odor(s) on fatigue and green-odor-responsible brain regions as revealed by PET. Chem Senses 2005, 30(SuppI I):i268-9.

6. Tokumo K, Tamura N, Hirai T, Nishio H: Effects of (Z)-3-hexenol, a major component of green odor, on anxiety-related behavior of the mouse in an elevated plus-maze test and biogenic amines and their metabolites in the brain. Behav Brain Res 2006, 166:247-52.

7. Sano K, Tsuda Y, Sugano H, Aou S, Hatanaka A: Concentration effects of green odor on event-related potential (P300) and pleasantness. Chem Senses 2002, 27:225-30.

8. Nakashima T, Akamatsu M, Hatanaka A, Kiyohara T: Attenuation of stress-induced elevations in plasma ACTH level and body temperature in rats by green odor. Physiol Behav 2004, 80:48I-8.

9. Akutsu H, Kikusui T, Takeuchi Y, Sano K, Hatanaka A, Mori Y: Alleviating effects of plant-derived fragrances on stress-induced hyperthermia in rats. Physiol Behav 2002, 75:355-60.

10. McNair D, Lorr M, Droppleman L: Mannual for the Profile of Mood States (POMS). San Diego, CA: Educational and Industrial Testing Service; 197I.

II. Oka T, Oka K, Hori T: Mechanisms and mediators of psychological stress-induced rise in core temperature. Psychosom Med 200I, 63:476-86.

12. Oka T, Oka K, Kobayashi T, Sugimoto Y, Ichikawa A, Ushikubi F, Narumiya S, Saper CB: Characteristics of thermoregulatory and febrile responses in mice deficient in prostaglandin EPI and EP3 receptors. J Physiol 2003, 55 I:945-54.

13. Oka T, Oka K: Age and gender differences of psychogenic fever: a review of the Japanese literature. Biopsychosoc Med 2007, I: I I.

14. Hayashida S, Oka T, Tsuji S: Cilnidipine lowered psychological stress-induced increase in blood pressure in a hypertensive man: A case report. Biopsychosoc Med 2007, I:I6.

15. Kim J, Ishibashi M, Nakajima K, Aou S, Hatanaka A, Oomura Y, Sasaki $K$ : Effects of green odor on expression of Fos-immunoreactivity in the paraventricular nucleus of the thalamus in forced swimming rats. Chem Senses 2005, 30(Suppl I):i266-7.

16. Otake K, Kin K, Nakamura Y: Fos expression in afferents to the rat midline thalamus following immobilization stress. Neurosci Res 2002, 43:269-82.

17. Spencer SJ, Fox JC, Day TA: Thalamic paraventricular nucleus lesions facilitate amygdale neuronal response to acute psychological stress. Brain Res 2004, 997:234-7.

18. Sasabe T, Kobayashi M, Kondo Y, Onoe H, Matsubara S, Yamamoto $\mathrm{S}$, Tsukada H, Onoe K, Watabe H, lida H, Kogo M, Sano K, Hatanaka A, Sawada T, Watanabe $Y$ : Activation of the anterior cingulate gyrus by 'Green Odor': a positron emission tomography study in the monkey. Chem Senses 2003, 28:565-72.

19. Bush G, Luu P, Posner Ml: Cognitive and emotional influences in anterior cingulate cortex. Trends Cogn Sci 2000, 4:2 I 5-22.

Publish with Bio Med Central and every scientist can read your work free of charge

"BioMed Central will be the most significant development for disseminating the results of biomedical research in our lifetime. "

Sir Paul Nurse, Cancer Research UK

Your research papers will be:

- available free of charge to the entire biomedical community

- peer reviewed and published immediately upon acceptance

- cited in PubMed and archived on PubMed Central

- yours - you keep the copyright 